\title{
Visual field loss in an elderly vasculopath: clinical significance of multimodal imaging
}

\author{
Christine Bourke, Kirk A J Stephenson (10 , Paul P Connell
}

Ophthalmology, Mater Misericordiae University Hospital, Dublin, Ireland

Correspondence to Dr Kirk A J Stephenson; kirkstephenson@hotmail.com

Accepted 31 August 2021

Check for updates

(C) BMJ Publishing Group Limited 2021. No commercial re-use. See rights and permissions. Published by BMJ.

To cite: Bourke $C$, Stephenson KAJ, Connell PP. BMJ Case Rep 2021;14:e245115. doi:10.1136/bcr-2021245115

\section{DESCRIPTION}

A 74-year-old man presented with acute onset right superonasal visual field loss and blurred vision. $\mathrm{He}$ had no other focal neurological symptoms, headache, jaw claudication or scalp tenderness. Medical history included coronary artery bypass grafting, hypertension and hypercholesterolaemia. Inpatient stroke work-up revealed $>70 \%$ internal carotid stenosis on Doppler ultrasound, normal neuroimaging and inflammatory markers.

Visual acuity (VA) was 6/9 in each eye, with normal colour vision and no relative afferent pupil defect. Confrontational visual fields detected monocular right eye superonasal quadrantanopia with full left eye visual field. Anterior segments were unremarkable and intraocular pressures were normal. Fundal examination showed a segmental Hollenhorst plaque in the inferotemporal primary retinal arteriole with associated intraretinal oedema (figure 1A). Fundus fluorescein angiography (FFA) confirmed the diagnosis of inferotemporal branch retinal artery occlusion (BRAO) (figure 1B); armto-eye time was delayed $(30 \mathrm{~s})$ suggesting ipsilateral carotid insufficiency. Optical coherence tomography (OCT) showed paracentral acute middle maculopathy (PAMM) corresponding to the ischaemic area, which was clearly delineated on en face infrared reflectance imaging (figures $1 \mathrm{C}$ and 2).

BRAO has an estimated incidence of 5 per 100 $000 .{ }^{12}$ It is caused by an acute interruption of arterial blood flow to the inner retina leading to ischaemic damage. ${ }^{3}$ The subjective symptoms (ie, reduced VA and/or field loss) depend on the retinal area affected; this patient retained normal VA as his fovea was spared. Retinal arterial emboli are visualised in $62 \%$ of BRAO, often occurring at bifurcation points, with temporal retinal arteries being involved in $98 \%$ of symptomatic cases. ${ }^{4}$ In an on-call setting, comprehensive multimodal imaging may not be readily available; however, OCT can prove invaluable, confirming/quantifying inner retinal oedema. ${ }^{5}$ PAMM is an OCT feature of inner retinal ischaemia, showing broad hyperreflective bands at the plane of the inner nuclear layer in affected zones (figure 2). PAMM may be seen in several inner retinal ischaemic conditions including branch/central RAO, retinal vein occlusion (RVO) and diabetic retinopathy (DR). ${ }^{6}$ While OCT angiography may serve as a non-invasive modality to demonstrate reduced flow in the affected quadrant, it cannot directly suggest carotid disease by delay in arm-to-eye time as in FFA. ${ }^{\text {? }}$

Treatment options for BRAO are limited, with results of thrombolysis being equal/worse than

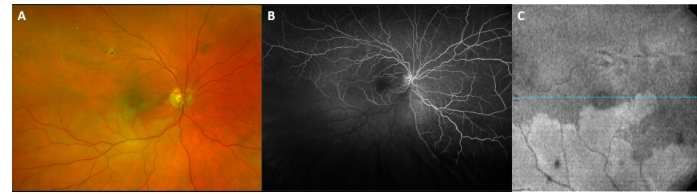

Figure 1 (A) Colour fundus photograph (Optos 'California', Optos PLC, Scotland, UK) of the right eye demonstrating a Hollenhorst plaque occluding the right primary inferotemporal branch retinal arteriole with white appearance of retinal oedema in the relevant distribution. There is an incidental inactive chorioretinal scar at the superotemporal vascular arcade. (B) Mid-phase (circa 50 s) fundus fluorescein angiogram (Optos 'California') of the right eye showing absent filling of the inferotemporal retinal arterioles and venules, consistent with BRAO.

(C) En face infrared reflectance optical coherence tomography image (Carl Zeiss MediTec, Dublin, California, USA) at the mid-retinal segmentation plane, clearly delineating the distribution of the inner retinal area supplied by the occluded arteriole. BRAO, branch retinal artery occlusion.

observation. ${ }^{8}$ Prognosis is dependent on whether BRAO is permanent (74\% present with $\mathrm{VA} \geq 6 / 12$, maintained in $89 \%$ of these) or transient $(94 \%$ present with $\mathrm{VA} \geq 6 / 12$, maintained in $100 \%)$. ${ }^{9}$ Retinal or anterior segment neovascularisation is rare $(<0.1 \%)$ due to either spontaneous reestablishment of inner retinal perfusion and/or rapidity of the ischaemic insult versus the gradual ischaemic stress of RVO/DR. ${ }^{39}$ Treatment of systemic risk factors (ie, hypertension, smoking, dyslipidaemia) protects against further life-threatening ischaemic events (eg, stroke) and the North American Symptomatic Carotid Endarterectomy Trial demonstrated benefit from carotid endarterectomy if $>70 \%$ carotid stenosis was present. ${ }^{10}$

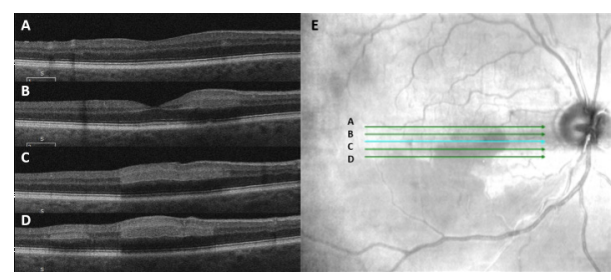

Figure 2 (A-D) Paracentral acute middle maculopathy (PAMM): spectral-domain OCT images (Carl Zeiss MediTec, Dublin, California, USA) demonstrating hyperreflective bands at the level of the inner nuclear layer, corresponding with the planes indicated in E). This is a sign of inner retinal ischaemia secondary to BRAO in this case. BRAO, branch retinal artery occlusion; OCT, optical coherence tomography. 


\section{Learning points}

- Although stroke must be excluded in elderly arteriopaths, visual field defects may also be caused by localised ophthalmic pathology (eg, monocular field defect due to retinal vascular occlusion, retinal detachment, optic neuropathy).

- En face optical coherence tomography (OCT) and OCT angiography are very useful diagnostic adjuncts to more invasive imaging techniques (eg, fundus fluorescein angiography, indocyanine green angiography) especially in an on-call setting.

- Systemic management is the mainstay of treatment; branch retinal artery occlusion may prove as a warning sign, allowing medical (eg, hypertension, cholesterol, diabetes mellitus) and/ or surgical (eg, carotid endarterectomy) management.

Effective treatment for the retinal sequelae of BRAO is limited, but VA is maintained in the majority. BRAO should be considered a trigger for systemic vascular risk factor management and secondary prevention of further ischaemic events.

\section{Acknowledgements Photography Department Mater Misericordiae University} Hospital.

Contributors $\mathrm{CB}, \mathrm{KAJS}, \mathrm{PC}$ contributed to patient care, manuscript drafting and revision.

Funding The authors have not declared a specific grant for this research from any funding agency in the public, commercial or not-for-profit sectors.
Competing interests None declared.

Patient consent for publication Obtained.

Provenance and peer review Not commissioned; externally peer reviewed.

\section{ORCID iD}

Kirk A J Stephenson http://orcid.org/0000-0002-7462-7725

\section{REFERENCES}

1 Chang Y-S, Ho C-H, Chu C-C, et al. Risk of retinal artery occlusion in patients with diabetes mellitus: a retrospective large-scale cohort study. PLoS One 2018;13:e0201627.

2 Brown GC, Shields JA. Cilioretinal arteries and retinal arterial occlusion. Arch Ophthalmol 1979;97:84-92.

3 Mason JO, Shah AA, Vail RS, et al. Branch retinal artery occlusion: visual prognosis. Am J Ophthalmol 2008;146:455-7.

4 Ros MA, Magargal LE, Uram M. Branch retinal-artery obstruction: a review of 201 eyes. Ann Ophthalmol 1989;21:103-7.

5 Pettersen JA, Hill MD, Dechuck AM, et al. Intra-Arterial thrombolysis for retinal artery occlusion: the Calgary experience. Can J Neurol sci. 2005;32:507-11.

6 Rahimy E, Kuehlewein L, Sadda SR, et al. Paracentral acute middle maculopathy: what we knew then and what we know now. Retina 2015;35:1921-30.

7 Wu S-C, Villegas VM, Kovach JL. Optical coherence tomography angiography of combined central retinal artery and vein occlusion. Case Rep Ophthalmol Med 2018;2018:4342158-4.

8 Pettersen JA, Hill MD, Demchuk AM, et al. Intra-Arterial thrombolysis for retinal artery occlusion: the Calgary experience. Can J Neurol Sci 2005;32:507-11.

9 Hayreh SS. Ocular vascular occlusive disorders: natural history of visual outcome. Prog Retin Eye Res 2014;41:1-25.

10 Gasecki AP, Eliasziw M, Ferguson GG, et al. Long-Term prognosis and effect of endarterectomy in patients with symptomatic severe carotid stenosis and contralateral carotid stenosis or occlusion: results from NASCET. North American symptomatic carotid endarterectomy trial (NASCET) group. J Neurosurg 1995;83:778-82.

Copyright 2021 BMJ Publishing Group. All rights reserved. For permission to reuse any of this content visit

https://www.bmj.com/company/products-services/rights-and-licensing/permissions/

BMJ Case Report Fellows may re-use this article for personal use and teaching without any further permission.

Become a Fellow of BMJ Case Reports today and you can:

- Submit as many cases as you like

- Enjoy fast sympathetic peer review and rapid publication of accepted articles

- Access all the published articles

Re-use any of the published material for personal use and teaching without further permission

Customer Service

If you have any further queries about your subscription, please contact our customer services team on +44 (0) 2071111105 or via email at support@bmj.com.

Visit casereports.bmj.com for more articles like this and to become a Fellow 